\title{
2020 Küresel Ekonomik Krizi ve Kendi Kendine Yeterli Olma Konusunda Farklı Yaklaşımlar: 2020 Ocak - 2020 Mayıs
}

DOI: $10.26466 /$ opus.776585

*

\author{
Armağan Örki* - Mehmet Aydın Tol** - Nurullah Arıkan *** \\ * Dr. Öğr. Üyesi, T. C. İstanbul Rumeli Üniversitesi, İstanbul/Türkiye \\ E-Posta: a orkiavsar@hotmail.com ORCID: 0000-0002-6906-0031 \\ ** Yüksek Lisans Öğrencisi, T. C. İstanbul Rumeli Üniversitesi, İstanbul/Türkiye \\ E-Posta: mehmetaydintol@hotmail.com ORCID: 0000-0001-6405-9771 \\ *** Öğr. Gör., T. C. İstanbul Rumeli Üniversitesi, İstanbul/Türkiye \\ E-Posta: nurullah.arikan@rumeli.edu.tr ORCID: 0000-0002-8912-1559
}

\begin{abstract}
Öz
Tarih boyunca insanlı̆̆ın karşı karşıya kaldığı salgıılar olmuştur. Bu salgınların neredeyse herbiri, en az savaşlar kadar ölümcül olmuş ve kimisinin sosyal etkileri yüzlerce yıl etkisini göstermiştir. İnsanlı$\breve{g ̆ ı n ~ k a r s ̧ ı l a s ̧ t ı ̆ ̆ l ~ s o n ~ s a l g i n ~ i s e ~} 2019$ yılında Çin Halk Cumhuriyeti'nde ortaya çıkan ve kısa sürede küresel çapta kapsamını genişleten Covid-19 olmuştur. Salgın, să̆lık politikaları kadar ekonomi politikalarını da etkilemiş ve hükûmetlerin hızlı ve etkili kararlar almasını zorunlu kılmıştır. Bu çalışmada ise öncelikle küresel ekonomik krizlere ilişkin farkl kaynaklardan çeşitli örnekler ele alınarak bir inceleme yapılması yoluna gidilmiştir. Sonrasında ise yazına 2020 Küresel Ekonomik Krizi olarak giren krizin oluşum süreci ve nedenleri incelenmiş, yedi ülkenin bazı ekonomik göstergeleri 2019 yılı verileriyle karşılaştırılmıştır. İstihdam, tüketici fiyatları endeksi, dış ticaret ve ekonomik büyüme verilerinin 2019 ve 2020'nin aynı ayları arasındaki değişim tablolar aracılığıyla sunulmuş ve değişimleri yorumlanmıştır. Çalışmanın takip eden bölümündeyse kendi kendine yetebilir olma durumuna yer verilip sonuç kısmında genel değerlendirmeleri yapılmıştır. Ekonomik verilerdeki farklılık dikkat çekici bulunup ülkelerin en azından bazı sektörlerde önceden önem vermedikleri üretim sahalarına yönelmeleri sonucuna ulaşılmıştır.
\end{abstract}

Anahtar Kelimeler: küresel ekonomik kriz, Covid-19, 2020 ekonomik krizi. 


\title{
2020 Global Economic Crisis and Different Approaches to Self-sufficiency: January 2020 - May 2020
}

\begin{abstract}
Throughout history, there have been outbreaks facing humanity. Almost every one of these outbreaks has been as deadly as the wars, and some have had social effects for hundreds of years. The latest outbreak facing humanity has been Covid-19, which emerged in the People's Republic of China in 2019 and soon expanded its scope globally. The epidemic has affected economic policies as well as health policies and has forced governments to make quick and effective decisions. In this study, a review was conducted by examining various examples from different sources related to the global economic crises. Afterwards, the formation process and causes of the crisis, which entered the summer of 2020 as the global economic crisis, were examined and some economic indicators of the seven countries were compared with the 2019 data. The change in employment, consumer prices index, foreign trade and economic growth data between the same months of 2019 and 2020 is presented through tables and their changes are interpreted. In the following part of the study, self-sufficiency status was given and overall evaluations were made in the conclusion section. The difference in the economic data is remarkable and it has been concluded that countries should focus on production areas that they did not care about before, at least in some sectors.
\end{abstract}

Keywords: global economic crisis, Covid-19, 2020 economic crisis. 


\section{Giriş}

2020 Küresel Ekonomik Krizi ${ }^{1}$, Türkiye' de olduğu gibi farklı kıtalarda bulunan birçok devleti de etkisi altına almıştır. Krizin devam ettiği süreçte kısa, orta ve uzun vadeli kararlar alınmış ve hayata geçirilmiştir. Bu kararların ekonomiyle ilgili olanları, kısmen bile olsa ülkelerin kendi kendine yeterli olmasıyla bağdaştırılmıştır. Bu çalışmadaysa krizin ilk dönemi (2020 OcakMayıs arası) içinde alınan ekonomik kararlar özelinde kendi kendine yeterli olma konusuna değinilmiştir.

Çalışmada öncelikle küresel ekonomik krizlere ve ardından 2020 Küresel Ekonomik Krizi'nin ilk dönemine (Haziran 2020'ye kadar) yer verilmiştir. Devamında ise 2020 Küresel Ekonomik Krizi'nin nedenleri ile oluşum süreci incelenmiş, ekonomik göstergeler derlenmiş ve hesaplanmıştır. Takip eden bölümde kendi kendine yetebilir olma konusu incelenerek sonuç kısmına geçilmiştir.

Bu çalışma konusuyla ilişkili Covid-19 ilk kez Çin Halk Cumhuriyeti'nde $^{2}$ görülmüş, yüksek ateş ve kuru öksürük gibi tipik belirtileri olan, kronik hastalığı olan herkes ile yaşlılarda risk barındıran bir hastalıktır (Budak ve Korkmaz, 2020, s. 65). Bir hastalığın salgına dönüşmesinin çeşitli sonuçları olmaktadır. Her ekonomik krizin oluşumunda bir hastalık olma şartı bulunmasa da, hemen her salgının ekonomik ve/veya politik bir sonucu olabileceği öngörülebilmektedir. 1300'lü yıllarda vebadan ötürü Avrupa'da nüfusun önemli ölçüde azalmasıyla birlikte topraklar ekilememiş, serfler şehirlere gidince ücretli işçilik ortaya çıkmış, işgücünün azalmasıyla derebeyler ise serfleri daha ağır koşullarda çalıştırınca ayaklanmalar yaşanmış ve uzun vadede derebeylik düzeni yıkılmıştır (Dağlar Macar ve Asal, 2020, s. 225). Siyasal tarihte önemli bir değişime neden olan veba gibi, ekonomik krizler de uluslararası ilişkilerden kültüre, sosyal yaşamdan iç siyasete kadar etkilerini gösterebilmektedir.

\section{Küresel Ekonomik Krizler}

Ekonomik krizler üretimde daralma, fiyatlarda düşme, işsizlik oranında artış gibi durumların hızlı ve beklenmedik şekilde oluşmasıyla ortaya çık-

\footnotetext{
${ }^{1}$ Büyük Karantina, Koronavirüs Durgunluğu (Resesyonu), Covid-19 Durgunluğu, 2020 Borsa Krizi.

${ }^{2}$ Bundan sonra Çin olarak anılacaktır.
} 
maktadır (Marangoz ve Uluyol, 2010, s. 83). Ekonomik krizler, genel olarak reel sektör krizleri ve finansal krizler şeklinde sınıflandırılmaktadır. Ayrıca bu krizler, kendi aralarında da ayrılmaktadır. (Bkz. Tablo 1: Ekonomik Kriz Türleri)

Tablo 1. Küresel Ekonomik Kriz Türleri

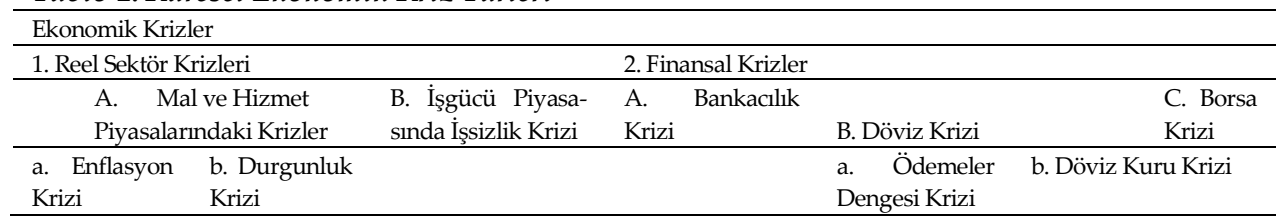

Kibritçioğlu, 2001, p. 175.

Ekonomik krizlerin nedenleri ve sonuçları farklı olabilmektedir. Her ne kadar ekonomik krizlerin oluşum nedenlerinin farklılık göstermesi görece normal görünse de, sonuçlarının farklılık göstermesi yazında sıklıkla incelenmiştir. Ayrıca sistemlerin sürdürülebilir ekonomiyle ilişiğine dönükte birçok çalışma bulunmaktadır. Örneğin Baum ve Lake (2003, ss. 345-346) dolaylı ve kısıtlı da olsa demokrasinin etkinliğini farklı kıstaslarla karşılaştırıp ortaya koymuştur. Buna karşın ekonomik yaşamın nasıl olduğu ile demokrasinin bir ilgisi bulunmadığına ilişkin de görüşler mevcuttur. Bu çalışmada ele alınan konu, kapsamı itibariyle demokratik olsun veya olmasın birçok ülkeye ulaşmış ve küresel bir kriz olduğu için, ekonomik krizlerin oluşumunda başlı başına rejim, sistem veya kurum incelemesinin katkı sağlayamayacağı görüşü üstüne kurulmuştur.

Ekonomik krizlerin farklı nedenleri bulunmaktadır. Bazı nedenler doğrudan krizleri etkilerken, bazılarının dolaylı olarak etkisini gösterdiği veya farklı nedenleri ortaya çıkardığı savunulmaktadır. Gökçen (2020, s. 208), 1994 Krizi ile ilgili olarak tüketim harcamalarındaki artş̧la ithalat artışının ihracat artışına göre daha yüksek seyretmesine işaret etmiştir. 1997 yılında Tayland'da ulusal para biriminden kaçışın Asya Krizini tetiklediği ve coğrafyasındaki diğer ülkelerde de aynı durumun yaşandığı aktarılmış ve özellikle de spekülatif (vurgun amaçlı) sermaye yatırımlarının bölge ülkelerini hızla terk etmesi en önemli etken olarak gösterilmiştir (Aydın, 2000, ss.1314). Ayrıca Aydın (2000, s. 16) krizin nedenleri arasında "aşırı yurtdışı borçlanma, banka sistemlerinin yetersiz denetimleri ve döviz kurlarmdaki dalgalanmala$r r^{\prime \prime}$ da göstermiştir. Akbay'ın (2011, s. 7) belirttiği yanlış ekonomi politikala- 
rının küresel çapta dengesizliklere yol açması, finansal piyasalarda etkin bir denetimin yapılamaması, riskin yaygınlaştırılması da genel için kabul edilebilecek nedenler arasındadır. Küresel çapta etkisini gösteren ekonomik krizlerin bölgeden bölgeye veya ülkeden ülkeye ulaşmasındaysa en önemli kanallardan biri olarak dış ticaret gösterilmiştir (Tabar ve Tokatlığlu, 2018, s. 34). Tabar ve Tokatlıoglu (2018, ss. 34-35) her ne kadar 2007 yılının son aylarında Amerika Birleşik Devletleri'nde (ABD) başlayan krize atıf yaparak Türkiye'ye ulaşmasını konu edinmiş olsa da, aslında değindikleri kredi, yatırım, üretici ve tüketicideki risk algısının artışı gibi noktalar tümevarım yapıldığında genel için yorumlanmaya da uygundur.

Küresel krizlere ilişkin çalışmasında Bocutoğlu ve Ekinci (2009, s. 80) Keynes'e attfta bulunmuş ve krizlerin süreleriyle şiddetlerinin temel belirleyiciliğinde belirsizliğin etkin olduğunu aktararak belirsizliğin azaltıldığında sürdürülebilir ekonominin daha mümkün hâle geldiğine işaret etmiştir. Gökalp (2003, ss. 164-165), güvenin oluşumunda açıklık, iletişim, katılım ve istikrarın önem barındırdığına işaret etmiş ve istikrarsızlı̆̆ın ise risk kavramıyla neredeyse aynı anlamda kullanıldığına değinmiştir. Özsağır (2007, s. 50) ise 2001 'de Türkiye'de yaşanan ekonomik krizin nedenleri arasında en çok vurgulanan konunun güven eksikliği olduğunu aktarmıştır.

Benzer veya aynı ekonomik krizlerin farklı sonuçlar doğurması genel çerçevede beklenmedik bir durumdur. Buna karşın aynı tipte yaşanan ekonomik krizler, zamana veya ülkeye göre farklı sonuçlara yol açabilmektedir. Borowy (2011, s. 1497) sağlık politikalarına olan ekonomik kriz etkileriyle ilgili çalışmasında iki ülke verilerini karşılaştırmış ve kültürel, ekonomik ve politik faktörlerin belirleyici olabileceği sonucuna ulaşmıştır. Örneğin 2001 Şubat Krizi, 1999 yılı sonu itibariyle ekonominin \%6 civarında küçülmesi, enflasyonun \%70 ve faizlerin ise \%100'ün üstüne çıkmasıyla kendisine zemin bulmuş; ancak siyasi krizin oluşmasıyla patlak vermiştir (Erdoğan, 2019, s. 88).

Ekonomik krizlerin hızla hissedilen sonuçları, hane halkının (tüketicinin), üreticinin ve hükûmetlerin tepkisiyle oluşmaktadır. 2008'de yaşanan krizde, küresel çaptaki talep düşüşüne karşın firmaların uyguladıkları yöntemleri Karabıyık ve Anbar (2010, s. 45) aktarmıştır ve bu yöntemler aynı zamanda birer sonuç olarak okunmaya da uygundur: "(...) üretimi azaltma, üretime ara verme, iş̧i çıkarma, yeni yatırımlar erteleme, varlık satışı ve maliyet tasarrufu..." Özatay'ın (2009, s. 142) belirttiği gibi ekonomilerin küçülmesiy- 
le gelir düzeyinin de düşmesi, ihraç mallarına olan talebi düşürdüğünden, ilgili sektörlerde üretim azalması ve işten çıkarmalar da oluşmaktadır. Tüketicilerin taleplerindeki azalma, firmaların üretim kısma veya işçi çıkarma gibi yöntemlere başvurmasıyla sonuçlanırken, devlet gelirlerinin azalması ve iç borçlanmanın artması beklenmektedir. Piyasaların tekrar canlanabilmesi için ise doğruluğu tartışmalı olsa da para basmadan vergi oranlarında değişikliğe gidilmesine kadar farklı yöntemler hükûmetlerce uygulamaya alınmaktadir.

Ekonomik krizlerin istihdam ve üretim üstündeki etkisine ilişkin yapılan bir çalışma, aşağıdaki grafiğin belli geçişlerinin daha iyi anlaşılabilmesine olanak tanımıştır. Türk Yan Sanayi Borsası'na dönük bir araştırmada katılımcıların yaklaşık 10'da 6'sı 2009'da üretim düzeylerinin düştüğünü aktarırken, yaklaşık \%55'i de istihdamın azaldığını paylaşmıştır (Dinçer, Ersun ve Ün, 2010, ss. 64-65). Grafik 1'de paylaşılan beş faktör, birbirleriyle ilgili olup hem sonrakinin nedeni hem de öncekinin bir sonucudur. Ayrica enflasyon, para basma, ihracatın ithalatı karşılayamaması, iflas ve benzerleri de grafiğin ilgili yerlerine yerleştirilebilir.

\section{Grafik 1. Ekonomik Krizlerde Sarmal Neden ve Sonuçlar}

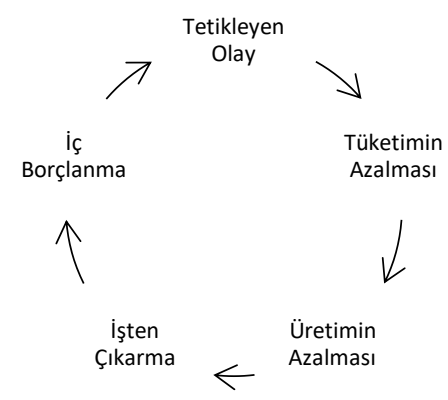

2008' de yaşanan krizin küresel sonuçları arasında büyümenin yavaşlaması ve dünya ticaret hacminde daralma gösterilmiştir (Yıldırım, 2010, s. 54). Bu iki veri küresel çapta ortak sonuç olarak kabul edilebilir. Buna karşın tek tek ülkeler incelendiğinde farklı sonuçlar ve etkiler yaşanabileceği ve farklı önlemlerin alınabileceği de çeşitli örnekler neticesinde anlaşılmaktadir. 1640'lı yıllardan 2008'e dek bazı ekonomik krizleri inceleyen Cicioğlu ve Yıldız (2018, s. 35-36), ortak noktaları olarak şunları paylaşmıştır: 
"Yoğun olarak görülen spekülatif hareketler, Fiyatlar genel düzeyinden aşırı sapmalar, Siyasal, askeri ve teknolojik değişimlerden etkilenme,

Dünya ekonomisinde serbestleşme ile krizler artık yerel olmaktan çok uluslararası boyutta gerçekleşmekte ve geniş bir alanda etkili olmakta,

Krizlerin ortaya çıkış anının tam olarak bilinmemesi ve bunun yanında ne kadar süre ile etkili olacă̆ının tahmin edilememesi."

2020 Ekonomik Krizi, diğer küresel ekonomik krizlerde olduğu gibi sadece ekonomide değil, farklı alanlarda da etkili olmuştur. Kriz, tek bir olayla oluşmamış; ancak Çin'de ortaya çıkan ve Dünya genelini etkisi altına alan salgınla beraber etkisini artırmıştır. Krizin ortaya çıkmasını tetikleyen süreç 2019'da başlamış ve ekonomik kriz tam anlamıyla 2020'de ortaya çıkmıştır.

\section{Küresel Ekonomik Krizi}

2020 Küresel Ekonomik Krizi'nin oluşum sürecinde, 2008 Krizi'nin etkilerinden bahsetmemek mümkün değildir. Ekonomik yaşamda gerçekleşen bir olayın doğrudan veya dolaylı olarak bir başka olayı doğurması veya şekillendirmesi kabul edilmektedir. Buna karşın 2020'de yaşanan krizin tetikleyicisi Çin'de başlayan ve küresel bir salgına dönüşen hastalık olmuş, ilerleyen süreçte farklı etkenlerle kapsamı ve şiddeti yükselmiştir.

\section{Küresel Ekonomik Krizi'nin Nedenleri ve Oluşum Süreci}

Söz konusu kriz, tipi itibariyle hem reel sektör krizleri içinde hem de finansal krizler içinde ele alınmaya uygundur. Çıkış noktası olarak en azından bu çalışmanın hazırlandığı dönem itibariyle salgın hastalığın gösterilmesi mümkündür. Uluslararası seyahatlerden yurtiçi seyahatlere kadar seyahat kısıtlamalarının konulması hem turizmi hem de dış ticareti durma noktasına getirirken, dolayısıyla üretim azalmış ve bu da işten çıkarma gibi seçeneklerin uygulanmasına yol açmıştır. Kriz, ilk etkilerini uluslararası piyasalarda göstermiş ve ardından petrol üretimi konusunda Rusya Federasyonu ${ }^{3}$ ile Suudi Arabistan arasındaki anlaşmazlıkla derinleşmiştir.

2020 Küresel Ekonomik Krizi'nin oluşumunda tetikleyici birer faktör olarak gösterilebilecek dört ana nedenden bahsetmek mümkündür. Bunlar

\footnotetext{
${ }^{3}$ Bundan sonra Rusya olarak anılacaktır.
} 
salgın, karantina süreci, dış ticaret ve uluslararası piyasalardaki değişim ve petrol konusundaki anlaşmazlık olarak özetlenebilir. Ayrıca hepsinin birbiriyle bağlantılı olduğu, doğrudan birbirlerinden etkilendikleri de dikkate alınmalıdır.

Salgın: Göğebakan (2020) salgınların dörde ayrıldığını, pandeminin ise bu dört sınıf içinde farklı ülke ve kıtalarda görülmesi durumu olduğunu aktarmıştır. Pandemilerin ise ekonomiyi farklı açılardan etkilediği ve ek olarak bireylerin beklenmedik davranışlar göstermesine neden olabileceği üstünde durulmuştur (Kılıç, 2020, s. 76). Yatırımcılar özelinde daha önce değinilen güven konusu, salgınlarla birlikte tekrar ağırlık kazanabilmektedir.

Karantina: Ülkelerin karantina uygulamalarında farklılıklar olmuştur. Örneğin Türkiye'de 21 Mart 2020'de 65 yaş üstü ile kronik hastalığı olanlara sokağa çıkma yasağı getirilmiş ve 4 Nisan'da ise 20 yaş altı gençler de bu yasağa dahil edilmiştir (Budak ve Korkmaz, 2020, s. 73). Seyahat kisıtlama ve yasaklamalarının birer sonucu olarak uçuşlardan otel rezervasyonlarına kadar çeşitli iptaller yaşanmış ve emek yoğun bir sektör olan turizmdeki istihdamın düşmesine neden olmuştur (Bahar ve Çelik İlal, 2020, s.129). Sadece turizmin etkilenmediği, turizm sektörüyle birlikte ulaşımdan tarıma kadar farklı sektörlerinden dolaylı veya doğrudan bu durumdan etkilenerek daralmaya gittiği bilinmektedir. Ayrıca Avrupa'nın en çok turist çeken kıta oluşu, 2018 verilerine göre en çok turizm harcaması yapan ülkelerin ise Çin'le birlikte ABD ve Almanya olması da dikkate değer bir ayrıntı olmuştur (UNWTO' dan aktaran Bahar ve Çelik İlal, 2020, s. 131).

Dış Ticaret ve Uluslararası Piyasalar: Salgının, hammadde, ara girdi ve son ürün açısından önemli bir tedarikçi olan Çin'de ortaya çıkması tedarik zincirine olan etkiyi güçleştirmiştir (Karlı ve Tanyaş, 2020, s. 180). Bunda etkili olan ise enfekte bireyler ile kontamine (temaslı) emtianin hizlıca yayılması olarak gösterilmiştir (Temel ve Ertin, 2020, s. 64). Kılıç (2020, s. 76) çalışmasında uluslararası piyasalarda yaşananların Türkiye' de de yaşandığı sonucuna ulaşmış, yatırımcıların farklı seçeneklere yönelebileceğini aktarmiştır. 
BIST $^{4}$ 100, FTSE 5 100, Nikkei ${ }^{6} 225$, Hang Seng 7 , NYSE ${ }^{8}$ gibi borsalarda 19 Mart ile 23 Mart tarihleri arasında büyük kırılmalar yaşanmıştır. Buna karşın Amerikan buğdayı ve özellikle de portakal suyu beklenmedik ilgiyle karşılaşmıştır. "Amerikan pamuk numara iki" ve "Londra şeker" ise dikkate değer bir dalgalanmaya maruz kalmamıştır. Emtiadaki bu durum ise küresel ekonomide yatırımcının tutum ve tercihlerine ilişkin ipucu vermektedir.

Petrol: Pandemiyle ilgili alınan kararların petrole olan talebi doğrudan etkilemesi, petrol üretimi konusundaki fikir ayrıllğının temelini oluşturmuştur. Rusya ile Suudi Arabistan arasında "petrol savaşı" olarak geçen süreçte Suudi Arabistan'ın lokomotifi olduğu Petrol İhraç Eden Ülkeler Örgütü (OPEC) fiyatların düşmesini önlemek için üretimi kısma kararı almış; ancak Rusya bu kararı kabul etmeyerek üretimi düşürmeyeceğini duyurmuştur. Buna karşı Suudi Arabistan da üretimini artıracağını duyurarak petrol fiyatlarının iyice düşmesine zemin hazırlamıştır.

Kriz, önceki krizlerde olduğu gibi tüketiciler üstünde etkili olmuştur. Elektronik ortamda yapılan alışverişlerde (e-ticaret) tıbbi ürünler, bebek ürünleri ve temizlik ürünleri ilgi görürken, giyim, otomotiv, mücevher ve seyahat harcamalarında yüksek oranda düşüş gözlenmiştir (Güven, 2020, s. 258). Ulusal düzeyde yapılan bir diğer çalışmadaysa fiziki kredi kartı kullanımının azaldığı, özellikle vadesiz mevduatlarda artış yaşandığı gözlenmiştir (Ersoy, Gürbüz ve Fındıkçı, 2020, s. 159).

Ekonomik krizlere karşı başvurulan yöntemler krizin kapsamına ve türüne, zamanına, ülkenin politik kültürüne ve vatandaşların tüketim eğilimine göre değişiklik gösterebilmektedir. Gopinath (2020), krizin üç aşamalı bir sürece yayılacağını aktarmış, bunları ise ülkelerin krize girdiği dönem, çıktıkları dönem ve salgına çözümün bulunduğunda oluşan çıkış dönemi olarak sıralamıştır. Dolayısıyla ele alınan yöntemler, krize girilen dönem için yapılan uygulamalar olmuştur.

Hastalığın bulaş hızını azaltmaya dönük atılan bazı adımlar doğrudan ekonomik sonuçlara da neden olmuştur. Örneğin 3 Nisan 2020 tarihinde

\footnotetext{
${ }^{4}$ Borsa Istanbul.

${ }^{5}$ Londra Borsası.

${ }^{6}$ Tokyo Borsası.

${ }^{7}$ Hong Kong Borsası.

${ }^{8}$ New York Borsası.
} 
Türk Hava Yolları (THY) tarafından icra edilen yurtiçi uçuşlar durdurulurken, yurtdışı uçuşlar da 14 Nisan 2020'de durdurulmuş ve 16 Nisan'da ise üç ay süreyle işçi çıkartılmasının yasaklanmasına ilişkin düzenleme yasama erki tarafından kabul edilmiştir (Budak ve Korkmaz, 2020, ss. 73-74). Uçuşlarla ilgili kısıtlamalar aslında bir ay öncesinde, Mart'ta başlamış; ancak en kapsamlı şeklini Nisan'da alabilmiştir. Örneğin İran İslam Cumhuriyeti ile yapılan uçuşlar 26 Şubat'ta durdurulmuştur (Macit ve Macit, 2020, s. 107). Hastalığın yayılmasını önleme amacı dışında, doğrudan ekonomik kararlar da alınmıştır. Hem 2020 içinde alınan kararlar hem de ekonomik koşullar, krize girilen, çıılan ve salgına çözüm bulunan dönemdeki ekonomik görünümü etkileyebilmektedir.

\section{Seçilmiş Ülkelerden Veriler}

Kişi başına nominal gayri safi millî hasıla (GSMH) sıralamasında Türkiye'nin konumu da dikkate alınarak ilk üç gruptan toplam yedi ülkenin bazı verileri karşılaştırmalı olarak incelenmiştir. Dünya Bankası (2020) verilerine göre Türkiye ile birlikte onu takip eden Bulgaristan ve Brezilya ile daha üst sıralarda yer alan ABD, Almanya, Çin ve İtalya verileri incelenmiştir.

Yedi ülkenin 2019 ve 2020 yıllarının ilk altı aylarına dair işsizlik, enflasyon, ihracat, ithalat, dış ticaret açı̆̆ı, ekonomik büyüme verileri ve/veya veri değişim oraları aşağıda farklı tablolarda sunulmuştur. İlk olarak işsizlik oranlarındaki değişim (Tablo 2) farklı kaynaklardan yararlanılarak oluşturulmuştur. 2019 yılı için genel ortalama dikkate alınarak aynı kaynaktan yararlanılmış; ancak 2020 için farklı aylardaki işsizlik oranları dikkate alınarak değişim hesaplanmıştır.

Tablo 2. Seçilmiş Yedi ülke İşsizlik Verileri (Değişim \%)

\begin{tabular}{llllllll}
\hline Ülke / Periyot & ABD & Alm. & İtl. & Tr. & Çin & Bulg. & Brz. \\
\hline $2019-2020.04$ & & & & -5.11 & & & \\
\hline $2019-2020.05$ & & 28.28 & -21.05 & & & 107.37 & 6.78 \\
\hline $2019-2020.06$ & 201.63 & & & & 31.94 & & \\
\hline
\end{tabular}

2019 verileri için kaynak: The World Bank, 2020. ${ }^{2} 2020$ verileri için kaynaklar: Trading Economics, 2020h, 2020d, 2020f, 2020g, 2020c, 2020b, 2020a. (Ülke sırasına göre) ${ }^{10}$

\footnotetext{
${ }^{9}$ Kaynak, ILOSTAT verilerinden yararlanmıştır.

${ }^{10}$ Kaynaklar ülke sırasına göre BLS, Almanya Federal Istatistik Ofisi, ISTAT, TÜiK, NBS, Bulgaristan Çalışma ve Sosyal Politikalar Bakanlığı, IBGE verilerinden yararlanmıştır.
} 
Tablo 2'de ABD'deki işsizlik oranlarındaki artış son derece dikkat çekicidir. 2019'da \%4'ün altında olan isssizlik oranları 2020 Haziran'da \%11'in üstüne çıkmıştır. Salgından uzun süre etkilenen İtalya' da ise işsizlik oranları 2019 ' da \%10'un altındayken 2020 Mayıs'ta \% 8' in altına inmiştir.

Ülkelerin enflasyonlarındaki değişim de salgına karşı alınan ekonomik önlemler konusunda fikir verebilir. Bu nedenle Tablo 3'te tüketici fiyatları endeksi (TÜFE) hazırlanmış ve yedi ülkenin 2019'daki ilgili ayı ile 2020'deki aynı ayı arasındaki değişim oranı hesaplanmıştır. Örneğin ABD'de 2019 Ocak TÜFE oranı bir yılda \%56.25 artmıştır. Karşılaştırılan veriler sadece ay temellidir. Yani Mart 2019' da 1.9 olan oran Mart 2020' de 1.5 olmuş, dolay1sıyla \%21.05 civarında düşüş (azalış) yaşanmıştır.

Tablo 3. Seçilmiş Yedi Ülke TüFE Verileri (Değişim \%)

\begin{tabular}{llllllll}
\hline 2019/2020 & ABD & Alm. & İtl. & Tr. & Çin & Bulg. & Brz. \\
\hline Ocak & 56.25 & 21.42 & -44.44 & -40.29 & 217.64 & 40.00 & 10.84 \\
\hline Şubat & 53.33 & 13.33 & -70.00 & -37.11 & 246.66 & 15.62 & 3.08 \\
\hline Mart & -21.05 & 7.69 & -90.00 & -39.82 & 86.95 & -16.66 & -27.94 \\
\hline Nisan & -85.00 & -55.00 & -100.00 & -43.89 & 32.00 & -51.35 & -51.41 \\
\hline Mayis & -94.44 & -57.14 & -125.00 & -39.12 & -11.11 & -62.85 & -59.65 \\
\hline Haziran & -62.50 & -43.75 & -128.57 & -19.72 & -7.40 & -42.85 & -36.79 \\
\hline
\end{tabular}

Trading Economics, 2020e. ${ }^{11}$

2019 verileriyle 2020 verilerinin karşılaştırılmasında ayrıca seçili ülkelerin dış ticaret verilerinin incelenmesine de ihtiyaç duyulmuştur. Bu yüzden Tablo 4'te ihracat verilerindeki değişim derlenip hesaplanmış, Tablo 5'te ithalat verileri için aynı işlem uygulanmıştır. Ardından Tablo $6^{\prime}$ da ise dış ticaret açıkları ve/veya fazlalıklarındaki değişim derlenip hesaplanarak tablolaştırılmıştır.

Tablo 4. Seçilmiş Yedi Ülke İhracat Verileri (Değişim \%)

\begin{tabular}{llllllll}
\hline 2019/2020 & ABD & Alm. & İtl. & Tr. & Çin & Bulg. & Brz. \\
\hline Ocak & -0.32 & -4.72 & -0.55 & 11.94 & - & 3.29 & -19.54 \\
\hline Şubat & 1.18 & -3.61 & 2.79 & 8.06 & - & -0.68 & -1.04 \\
\hline Mart & -9.22 & -9.69 & -15.27 & -13.02 & -6.80 & -9.75 & 8.73 \\
\hline Nisan & -29.11 & -33.38 & -76.69 & -37.74 & 3.48 & -74.36 & -5.72 \\
\hline Mayıs & -36.25 & - & - & -37.32 & -3.28 & - & -13.14 \\
\hline
\end{tabular}

International Trade Centre, 2020a.

\footnotetext{
${ }^{11}$ Kaynak BLS, Almanya Federal istatistik Ofisi, ISTAT, TÜiK, NBS, NSI, IBGE verilerinden yararlanmıştır.
} 
Tablo 4 ve Tablo 5'in birbirinden bağımsız incelenmesiçok doğru bulunmasa da dış ticaret performanslarına ilişkin fikir verebileceği düşünülmüştür. Örneğin Tablo 4'te Nisan verileri incelendiğinde İtalya ile Bulgaristan'ın ihracatında önemli bir düşüş yaşandığı görülmektedir.

Tablo 5. Seçilmiş Yedi Ülke İthalat Verileri (Değişim \%)

\begin{tabular}{llllllll}
\hline 2019/2020 & ABD & Alm. & İtl. & Tr. & Çin & Bulg. & Brz. \\
\hline Ocak & -4.13 & -4.20 & -1.13 & 24.39 & - & 1.39 & -1.29 \\
\hline Şubat & -4.14 & -6.58 & -4.56 & 13.49 & - & -4.22 & 5.03 \\
\hline Mart & -6.55 & -6.42 & -19.83 & 8.16 & -0.46 & -8.22 & 10.61 \\
\hline Nisan & -20.56 & -24.32 & -72.80 & -21.67 & -13.77 & -74.57 & -14.80 \\
\hline Mayıs & -25.44 & - & - & -23.99 & -16.43 & - & -10.53 \\
\hline
\end{tabular}

International Trade Centre, 2020b.

Tablo 4 için örneği sunulan Nisan verilerinde İtalya ile Bulgaristan'ın ön planda olması gibi, Tablo 5'te de her iki ülkenin ithalatında da önemli bir düşüş yaşandığı gözlenmektedir.

Tablo 6. Seçilmiş Yedi ülke Dış Ticaret Açı̆̆ı Verileri (Değişim \%)

\begin{tabular}{llllllll}
\hline 2019/2020 & ABD & Alm. & İtl. & Tr. & Çin & Bulg. & Brz. \\
\hline Ocak & -10.24 & -8.16 & 63.21 & 95.06 & - & -23.15 & -10.86 \\
\hline Şubat & -15.61 & 11.62 & 80.55 & 50.24 & - & -31.37 & -24.42 \\
\hline Mart & -0.52 & -23.70 & 21.52 & 174.96 & -38.98 & 5.00 & 3.33 \\
\hline Nisan & -6.06 & -80.22 & -125.20 & 59.32 & 227.70 & -75.84 & 15.65 \\
\hline Mayıs & -7.30 & - & - & 99.81 & 51.05 & - & -20.03 \\
\hline
\end{tabular}

International Trade Centre, 2020a ve 2020b.

Tablo 6, seçili ülkelerin dış ticaretlerindeki değişimi göstermektedir. İki yılın aynı ayındaki dış ticaret açığının (veya fazlasının) farkı derlenip hesaplanmış ve tabloya yerleştirilmiştir. Örneğin ABD'de Ocak'ta yazılı olan oran, 2019 Ocak ile 2020 Ocak arasındaki değişimi göstermektedir. Dış ticaret açı̆̆ı \%10.24 oranında azalmıştır. Bir diğer ifadeyle açık veya fazlalığın değişimi gösterilmiş olup her artının açık ve her eksinin fazla olduğu düşünülmemelidir. Örneğin Almanya'nın Şubat verileri düşünüldüğünde, dış ticaret fazlasında artış olduğu anlaşılmaktadır.

Almanya, ilgili aylarda hem 2019 yılında hem de 2020 yılında dış ticaret fazlası vermiştir. Buna karşın özellikle 2020 Nisan' daki dış ticaret fazlası, bir önceki yılın aynı ayına göre \%80 civarında azalmıştır. İtalya, dış ticaret fazlası veren bir ülkedir. 2019'daki dış ticaret fazlası, 2020'deki aynı dönemlerde artmıştır. Nisan verileri incelendiğinde ise açık vermiş; bir önceki yıl verdiği fazlalık açığa dönüşmüştür. Tabloda Türkiye'nin dış ticaret açığı 
verisi de İtalya gibidir; ancak söz konusu artış, dış ticaret açığında gerçekleşmiştir. Çin verilerinde de ilgili dönemlerde dış ticaret fazlalığı oluşmuştur; ancak sadece 2019 Mart'taki fazlalık 2020 Mart' a göre daha yüksek oluştuğu için fark düşüşü orana yansımıştır. Bulgaristan, Tablo 4, 5 ve 6 'da sürekli diş ticaret açığı vermiş bir AB ülkesidir ve özellikle Nisan 2020'de toplam dış ticareti önemli ölçüde azalmış, ihracatı yine de ithalatı karşılayamamıştır.

Tablo 7. Seçilmiş Yedi Ülke Ekonomik Büyüme (GSYï) Verileri (Değişim \%)

\begin{tabular}{llllllll}
\hline Ülke/ Dönem & ABD & Alm. & İtl. & Tr. & Çin & Bulg. & Brz. \\
\hline $2019 / 2020$ İlk Çeyrek & -356.52 & -1266.66 & -3133.33 & -655.55 & -80.32 & -217.64 & -581.81 \\
\hline
\end{tabular}

IMF, 2020.

Ekonomik büyüme için gayri safi yurtiçi hasıla (GSYIHH) verileri incelenmiştir. Millî gelirin hesaplanmasında tüketim harcamaları, yatırım harcamaları, hükûmet harcamaları ile ihracat tutarından ithalat tutarının çıkartılmasından kalan sonuç toplanmaktadır (Gökçen ve Yerdelen Tatoğlu, 2016, s. 165). ABD ekonomisi 2019 'da büyürken 2020'nin ilk çeyreğinde \%350'yi aşkın oranda küçülmüştür. Seçili ülkelerin ekonomileri 2020'nin ilk çeyreğinde negatif yönlü büyürken, sadece Çin ekonomisinde pozitif yönlü büyüme olmuştur; ancak Çin'in büyüme hızı da önceki yıla göre daha düşük orandadır.

\section{Kendi Kendine Yeterli Olma}

Ekonomik krizler sonrasında hem ekonomistler hem de ilgili disiplindeki araştırmacılar tarafından bir dizi deneyimin kazanıldığı yazına aktarılmıştır. Atlatılan zorlu süreçlerden alınan dersler, olası diğer krizlere karşı daha sağlam ve sürdürülebilir bir ekonomik yaşam için önkoşul gibi kabul görmüştür. Örneğin Göktaş (2000, ss. 8-10) Güneydoğu Asya krizinden kambiyo politikaları, borçlanma politikaları, sermaye politikaları, finans sisteminin yapısı, yatırım politikaları gibi farklı deneyimler edinildiğini çalışmasinda aktarmıştır.

2020 Küresel Ekonomik Krizi'nin nedenleri ve buna karşı alınan önlemler (başvurulan yöntemler) incelendiğinde mevcut sıkıntıların hızlıca çözülebilmesine odaklanıldığı görülmektedir. Hükûmetler ve ilgili kuruluşlar özelinde bu tutum gayet anlaşılabilir, normal bir davranıştır. Öte yandan 
orta ve uzun vadede salgından ve ekonomik krizden ders alınarak değerlendirilebilecek farklı yaklaşımlar da söz konusudur.

Orta ve uzun vadede kendi kendine yetebilir olma konusunda özellikle 2020'nin ilk altı ayındaki süreç bazı sektörleri ön plana çıkarmıştır. Bunlardan birincisi gıda güvenliğidir. Ayrıca katma değeri düşük (tıbbî maske gibi) ürünleri üretip temin edebilme konusunda da hassas davranılması gereği ortaya çıkmıştır. Örneğin 2020 Mart'ta Avrupa Birliği (AB) üye ülkelerindeki ölüm oranlarının artması maske ve benzeri sağlık araç ve gereçlerinin gönderimi konusunda sorun oluşturmuş, gerekli yardımları önce Çin ve sonrasında Fransa ve Almanya gibi bazı üyeler, sonrasındaysa yüklü olarak Türkiye ile Rusya yapmıştır (Ünalp Çepel, 2020, s. 40).

Kuramsal çerçevede otarşi ile ifade edilen kendi kendine yeterli olma stratejisi, Goldstein ve Pevehouse (2014/2017, s. 380) tarafından yüksek maliyetli bulunmuş ve işbirliği yapan devletler karşısında karşılaştırmalı üstünlüğü bulunmayan otarşik politikaların başarısız olacağı ifade edilmiştir. Ekonomik kalkınma, piyasadaki aksaklıkların giderilmesi, hazineye gelir sağlama gibi amaçlardan ötürü dış ticaret konusu göz ardı edilemeyecek politik ve ekonomik bir süreçtir (Seyitoğlu, 2007, ss. 139-140). Dolayısıyla otarşik politikaların varlığını sürdürebilmesi olanaksız bulunmuştur.

\section{Kendi Kendine Yeterli Olmayla İlgili Farklı Kuramlar ve Yaklaşımlar}

Ekonomilerin iyileştirilmesi için başvurulan farklı politikalar olmuştur. Planlı ekonomiler ve tümüyle piyasaların serbest bırakıldığı ekonomiler dişındaki, görece arada kalan ekonomilerde uygulanan bu politikalar kimi değişkenlere bağlı olarak başarılı olabilmektedir. Özellikle 2020 Küresel Ekonomik Krizi'nin ilk altı ayında tam anlamıla neoliberal teorinin önerdiği şekliyle ekonomiye müdahale etmeyen bir ülke olmadığı anlaşılmıştır. Her devlet, en azından vergi alarak veya düzenleyici (ve denetleyici) görevini yerine getirerek ekonomilerine müdahale etme durumundadır.

Dış ticarete ve ülke ekonomisine ilişkin farklı kuram ve yaklaşımlar (mutlak üstünlükler ve karşılaştırmalı üstünlük kuramları gibi) karşılaşılan özel durumlar ve ideolojiler 1şı̆̆ınde gelişmiştir. Buna karşın işbu konuyla ele alınanlar "güçlü devlet" veya en azından "güçlü ekonomi" kapsaında kriz anında değerlendirilmeye uygun olanlardır. Gümrük tarifeleri ve ihracatın özendirilmesi gibi araçlarla dış ticaret hedeflerine ulaşılmaya çalışıl- 
ması da ekonominin, yani devletin gücünün sürdürülebilirliği açısından değerlidir.

Güçlü bir devlet oluşturma çabasının bir ürünü olarak yorumlanan merkantilizm, ihracatın artırılıp ithalatın sınırlandırılması gerektiğini savunmuştur (Aka ve Ürünal, 2018, s.156-157). Kapitalizme dönük ilk hareket olarak tanımlanan merkantilizme göre değerli maden birikimi zenginliğin ölçütüdür ve bu yüzden uluslararası mal değişimi ekonominin temelini oluşturmaktadır (Kuyucuklu, 1982, s.20). Ayrıca dış ticarette tarafların birlikte kazanç sağlaması mümkün değildir ve devletlerin ürün ithalatını sınırlandırıp hammadde ithal etmelerine, ithal edilen hammaddenin işlenip ihraç edilmesine odaklanılır (Seyidoğlu, 2007, s.21).

İthal ikâmesi, sübvansiyon ve tarife gibi araçlarla ithal edilen malların yerli firmalarca üretilmesine olanak tanıyan, ekonomik kalkınma sürecinde başvurulan bir politikadır (Goldstein ve Pevehouse, 2014/2017, s. 596). Diş ticarette korumacıllkta bir diğer seçenektir. Seyidoğlu (2007, s. 144-151) diş ticarette korumacılığı tutarlı gerekçelerle koruma (ulusal güvenlik, genç endüstri tezi, stratejik ticaret politikası, dampinge karşı koruma), belirli koşullarda geçerli nedenler (ödemeler bilançosunun iyileştirilmesi ve işsizliğin önlenmesi, ticaret hadlerinin iyileştirilmesi, ulusal pazarlık gücünü artırma) ve kişisel çıkarlara dayalı görüşler (düşük yabancı ücret, üretim maliyetlerini eşitleme, ulusal pazar görüşü) şeklinde sınıflandırmıştır.

\section{Sonuç}

Tarih boyunca insanlığın yüzleştiği salgınlar olmuştur ve bu salgınlarda en az savaşlardaki kadar insan yaşamını yitirmiştir. Geçtiğimiz yüzyıldan beri ülkelerin birbirleriyle etkileşimleri teknolojinin de sayesinde artmış, özellikle ekonomik olarak birbirlerine olan bağımlılıkları dış ticaretin büyümesine neden olmuştur. Hammadde, ara girdi ve son üründeki dış ticaret işlemleri, hem parasal hem de finansal alanda oluşabilecek ekonomik krizlerde domino etkisi yaratabilecek kapsama ulaşmıştır. Yani bir ülke veya ülke grubundaki kriz, çok kısa süre içinde merkez üssünden diğerlerine sıçrayabilmektedir.

İlk kez 2019 yılında Çin'de görünen salgın, 2020'nin ilk beş ayında Dünya'nın neredeyse her noktasına ulaşmıştır. Hükûmetler, hem salgının ülkeleri içindeki yayılımını önlemek hem ekonomilerini diğerlerine göre daha 
iyi seviyede tutabilmek hem de bağımlılıklarını azaltabilmek için çeşitli politikaları hayata geçirmek durumunda kalmıştır. Bu politikaların öncelikli belirleyicisi ise kendi kendine yetebilir olma olmuştur.

Politikalardan bağımsız bir şekilde çalışmada incelenen veriler hangi ülke politikasının daha işlevsel olduğu hakkında fikir vermeye uygun bulunmuştur. Örneğin ABD'deki işsizlik oranı, 2019 Haziran'dan 2020 Haziran'a kadar \%200 civarında artmıştır. TÜFE verilerindeyse özellikle İtalya'nın Nisan, Mayıs ve Haziran verileri dikkat çekmiştir. Zira minimum \%100 oranında TÜFE'de artış yaşanmıştır. Dış ticaret verilerindeyse İtalya'daki hem ihracat hem de ithalatta yaşanan daralma diğer ülke verilerine göre daha yüksek oranda olmuştur. Ayrıca Bulgaristan da diş ticarette hatırı sayılır ölçüde daralmaya gitmiştir. Türkiye verileri diğerleriyle karşılaştırıldığında daha iyimser bir tablo sunmuştur. Yalnızca tablolardaki veriler düşünüldüğünde, işsizlik oranlarındaki değişimle diş ticaret ve özellikle ihracat verilerinin paralel olması beklenmiştir. Bu beklentiye ilişkin bir ipucu ise bulunamamıştır. Özellikle ABD'ye ilişkin verilerde istihdam oranlarına bağlı olarak dış ticaretin daha fazla düşmüş olması beklenirken, istihdam verilerindeki değişim daha ılımlı olan iki Avrupa ülkesinde dış ticaretin düştüğü gözlenmiştir.

Çalışmada ulaşılan bir diğer sonuç, ülkelerin öncelikli olarak kendi toplumlarını düşünme durumunda olduklarıdır. Bu doğrultuda, AB örneğindeki gibi işbirliklerine şartsız güvenilmemesi gereği anlaşılmıştır. Ayrıca, ülkelerin katma değerleri dikkate alarak üretim yapmamaları, afet, savaş ve salgın gibi durumlara hazırlıklı olacak en azından altyapı ve işgücüne sahip olmaya odaklanmaları gereği de anlaşılmıştır. 


\title{
EXTENDED ABSTRACT
}

\section{Global Economic Crisis and Different Approaches to Self-sufficiency: January 2020 - May 2020}

\author{
* \\ Armağan Örki - Mehmet Aydın Tol - Nurullah Arıkan \\ İstanbul Rumeli University
}

Global Economic Crisis of 2020 has affected many countries, including Turkey. Its effects have been shown in a wide geography extending from China to the USA and required states to take economic measures.

In the study, firstly, global-based economic crises were mentioned. The types of economic crises have been emphasized and the consequences of which have been included. The causes and consequences of economic crises can be different. Therefore, it is not possible to talk about a single reality. Considering the reasons, it was observed that the 1994 Crisis and 1997 Thailand Crisis occurred for different reasons. Although the results of the crises are relatively similar, they are not always the same for all countries, for different reasons. While in some cases it may have political consequences leading to a change of government, sometimes it causes micro-scale economic results. Generally, a trigger event followed by a decrease in consumption, production, employment, and domestic borrowing respectively.

The 2020 Global Economic Crisis has not been a completely independent process from the 2008 Crisis. On the other hand, the trigger of the crisis in 2020 was the disease that started in China and turned into a global epidemic, and its scope and severity increased with different factors in the following process. The crisis in question is suitable to be addressed both within the real sector crises and financial crises. As the starting point, it is possible to show the epidemic disease at least as of the period in which this study was prepared. The imposition of travel restrictions from international travel to domestic travel brought both tourism and foreign trade to a halt, hence production decreased, leading to options such as layoffs. Subsequently, the 
disagreement between the two major producers on oil production facilitated the deepening of the crisis.

One of the issues that distinguishes the crisis from other examples is the events that triggered its formation: the epidemic, the quarantine process, the change in foreign trade and international markets, and the conflict in oil production. The epidemic especially caused a decrease in confidence and negatively affected investments. The quarantine process led to a decrease in consumption, and this reduced production. The decrease in production causes a decrease in employment. The fact that China, which is a supplier of raw materials, intermediate inputs and end products for many countries in foreign trade, is at the center of the epidemic, negatively affected both foreign trade and production. Especially in March, there was a rapid decrease in stock markets. The Organization of Petroleum Exporting Countries of which Saudi Arabia is the locomotive, decided to cut production in order to prevent the decrease in prices; however, Russia did not accept this decision and announced that it would not decrease production. Against this, Saudi Arabia announced that it would increase its production and prepared the ground for a further decrease in oil prices.

Working together with Bulgaria, Turkey, Brazil, USA, Germany, China and Italy have analyzed the data. Unemployment, inflation, exports, imports, foreign trade deficit, economic growth data and / or data exchange rates are presented in tables using different sources. The USA, which has observed a change of over $200 \%$ in unemployment data, took the lead. Consumer price index showed that the change in countries generally goes parallel to each other. Export and import data also pointed to a decrease in production. The foreign trade deficit, on the other hand, was relatively positive compared to the same month of the previous year, as exports and imports decreased together. Although the foreign trade deficit has decreased, it should not be forgotten that production (and consumption) has also decreased. The gross domestic product (GDP) has been preferred in order to observe economic growth. When the countries studied are compared, Italy experienced the biggest loss, while China experienced relatively less loss.

When the causes of the 2020 Global Economic Crisis and the measures taken against it are examined, it is seen that the focus is on solving the existing problems quickly. This attitude is understandable and normal behavior in particular for governments and related organizations. On the other hand, 
there are different approaches that can be evaluated by taking lessons from the epidemic and the economic crisis in the medium and long term.

In terms of being self-sufficient in the medium and long term, the process in the first six months of 2020 has brought some sectors to the fore. The first of these is food safety. In addition, the necessity to be sensitive about producing and supplying products with low added value (such as medical masks) has emerged.

In the first six months of the 2020 Global Economic Crisis, it is understood that countries intervened in the economy contrary to what the neoliberal theory suggests. Each state has intervened in their economy, at the very least, by taxing or exercising its regulatory (and supervisory) role.

It is a reality that humanity encounters and suffers losses, like epidemics and wars. With the effect of technology, it is known that states interact with each other significantly in foreign trade. The epidemic that appeared in China in 2019 reached almost every corner of the world in the first five months of 2020. Governments have applied various policies to prevent the spread of the epidemic within their countries, to keep their economies at a better level than others and to reduce their dependency. The primary determinant of these policies has been self-sufficiency. The fact that countries are primarily in a position to consider their own society is seen as the most important result obtained within the scope of the study.

\section{Kaynakça / References}

Aka, A. ve Ürünal, A. A. (2018). Türkiye'de dış ticaret uygulamaları: 4458 sayılı Gümrük Kanunu özelinde, Balkan Sosyal Bilimler Dergisi, 7(13), 154-170.

Akbay, O. S. (2011). Küresel finansal krizin kökenleri üzerine bir değerlendirme, Sosyal Bilimler Metinleri, 2, 1-13.

Aydın, S. (2000). Asya krizi ve sermaye hareketlerinin vergilendirilmesi, Maliye Dergisi, 133, 13-30.

Bahar, O. ve Çelik İlal, N. (2020). Coronavirüsün (Covid-19) turizm sektörü üzerindeki ekonomik etkileri, International Journal of Social Sciences and Education Research, 6(1), 125-139.

Baum, M. A. ve Lake, D. A. (2003). The political economy of growth: Democracy and human capital, American Journal of Political Science, 47(2), 333-347.

Bocutoğlu, E. ve Ekinci, A. (2009). Genel teori, küresel krizler ve yeniden maliye politikası, Maliye Dergisi, 156, 66-82. 
Borowy, I. (2011). Similar but different: Health and economic crisis in 1990s Cuba and Russia, Social Science E Medicine, 72(9), 1489-1498.

Budak, F. ve Korkmaz, Ş. (2020). Covid-19 pandemi sürecine yönelik genel bir değerlendirme: Türkiye örneği, Sosyal Araştırmalar ve Yönetim Dergisi, 1, 62-79.

Cicioğlu, Ş. ve Yıldız, A. (2018). Lale krizinden günümüze ekonomik krizler: Temel yaklaşımlar ve ortak özellikler, Uluslararası Yönetim ve Sosyal Araştırmalar Dergisi, 5(9), 25-38.

Dağlar Macar, O. ve Asal, U. Y. (2020). Covid-19 ile uluslararası ilişkileri yeniden düşünmek: Tarih, ekonomi ve siyaset ekseninde bir değerlendirme, İstanbul Ticaret Üniversitesi Sosyal Bilimler Dergisi, 19(37), 222-239.

Dinçer, S. E., Ersun, O. ve Ün, T. (2010). Global krizde Türk Yan Sanayi Borsası'nın genel durumu ve beklentileri, İstanbul: ITO Yayınları.

Dünya Bankası, (2020). GNI per Capita, Atlas Method (current US\$). 02.07.2020 tarihinde https://data.worldbank.org/indicator/NY.GNP.PCAP.CD sitesinden erişildi.

Erdoğan, N. (2019). 156 yıllık tarihi, ulusal ve uluslararası kimliği ile T. C. Ziraat Bankası A. Ş.nin Türk ekonomisindeki rolü ve 2001 Şubat ekonomik krizi sonrasındaki yeniden yapılandırma başarısı, Ufuk Üniversitesi Sosyal Bilimler Enstitüsü Dergisi, 16, 79-96.

Ersoy, H., Gürbüz, A. O. ve Fındıkçı, M. (2020). Covid-19'un Türk bankacılık ve finans sektörü üzerine etkileri: Alınabilecek önlemler. İstanbul Ticaret Üniversitesi Sosyal Bilimler Dergisi, 19(37), 146- 173.

Goldstein, J. S. ve Pevehouse, J. C. (2017). Uluslararası ilişkiler. (H. Özdemir, Çev.). (2. bs). Ankara: BB101. (Orijinal çalışmanın basım yılı 2014).

Gopinath, G. (2020). The great lockdown through a global Lens. International Monetary Fund, 25.06.2020 tarihinde https://blogs.imf.org/2020/06/16/the-greatlockdown-through-a-global-lens/ adresinden erişildi.

Göğebakan, T. (2020). Tarihteki diğer pandemiler: İnsanlık diğer ölümcül salgın hastalıklardan nasil kurtuldu?. VeriAnaliz, 30.06.2020 tarihinde https:/www.verianaliz.net/pandemi-tarihi-corona-covid19-veri-analizinfografik/ adresinden erişildi.

Gökalp, N. (2003). Ekonomide güven faktörü, Yönetim ve Ekonomi, 10(2), 163-174.

Gökçen, A. M. (2020). Cumhuriyetten günümüze Türkiye'de iktisat politikaları ve ekonomik gelişme. M. Zencirkıran (Der.), Dünden bugüne Türkiye'nin toplumsal yapısı içinde, (s. 191-220). (7. bs.). Bursa: Dora.

Gökçen, A. M. ve Yerdelen Tatoğlu, F. (2016). Kantitatif iktisat, İstanbul. 
Göktaş, A. (2000). Güneydoğu Asya krizinin maliye ve para politikaları açısından sonuçları, Maliye Dergisi, 133, 3-12.

Güven, H. (2020). Covid-19 pandemik krizi sürecinde e-ticarette meydana gelen değişimler, Avrasya Sosyal ve Ekonomi Araştırmaları Dergisi, 7(5), 251-268.

IMF. (2020). Real GDP growth, 26.07.2020 tarihinde https://www.imf.org/external/datamapper/NGDP_RPCH@WEO/OEMD C/ADVEC/WEOWORLD/ sitesinden erişildi.

International Trade Center, (2020a). International trade in goods - Monthly exports 2002-2020. 23.07.2020 tarihinde http://www.intracen.org/itc/marketinfo-tools/statistics-export-country-product-monthly/ sitesinden erişildi.

International Trade Center, (2020b). International trade in goods - Monthly imports 2002-2020, 24.07.2020 tarihinde http://www.intracen.org/itc/marketinfo-tools/statistics-import-country-product-monthly/ sitesinden erişildi.

Karabıyık, L. ve Anbar, A. (2010). Küresel ekonomik krizin doğrudan yabancı yatırımlar üzerindeki etkisi. Muhasebe ve Finansman Dergisi, 46, 44-57.

Karlı, H. ve Tanyaş, M. (2020). Pandemi durumunda tedarik zinciri risk yönetimine ilişkin öneriler, İstanbul Ticaret Üniversitesi Sosyal Bilimler Dergisi, 19(37), 174-190.

Kılıç, Y. (2020). Borsa İstanbul'da COVID-19 (koronavirüs) etkisi. Journal of Emerging Economies and Policy, 5(1), 66-77.

Kibritçioğlu, A. (2001). Türkiye'de ekonomik krizler ve hükümetler: 1969- 2001. Yeni Türkiye Dergisi Ekonomik Kriz Özel Sayısı I, 7(41), 174-182.

Kuyucuklu, N. (1982). İktisadi olaylar tarihi. İstanbul.

Macit, A. ve Macit, D. (2020). Türk sivil havacilık sektöründe Covid-19 pandemisinin yönetimi, Avrasya Sosyal ve Ekonomi Araştırmaları Dergisi, 7(4), 100116.

Marangoz, M. ve Uluyol, O. (2010). Küresel ekonomik krizin tüketicilerin harcama ve tasarruf eğilimleri üzerine etkilerinin belirlenmesine yönelik bir araştırma, Muhasebe ve Finansman Dergisi, 45, 82-96.

Özatay, F. (2009). Finansal krizler ve Türkiye, İstanbul.

Özsağır, A. (2007). Ekonomide güven faktörü, Elektronik Sosyal Bilimler Dergisi, $6(20), 46-62$.

Seyidoğlu, H. (2007). Uluslararası iktisat: Teori, politika ve uygulama, (16. bs). İstanbul: Güzem Can Yayınları.

Tabar, Ç. ve Tokatlığlu, M. (2018). Küresel ekonomik kriz döneminde Türkiye'de uygulanan vergi politikalarının değerlendirilmesi. International Journal of Public Finance, 3(1): 27-46. 
The World Bank, (2020). Unemployment, total (\% of total labor force) (modeled ILO estimate). 20.07.2020 tarihinde https://data.worldbank.org/indicator/SL.UEM.TOTL.ZS?view=map sitesinden erişildi.

Temel, M. Kemal ve Ertin, H. (2020). 1918 grip pandemisi kıssasından COVID-19 pandemisine hisseler, Anadolu Kliniğ i Tıp Bilimleri Dergisi, 25 (Covid19 Özel Sayısı), 63-78.

Trading Economics, (2020a). Brazil unemployment rate. 23.07.2020 tarihinde https://tradingeconomics.com/ brazil /unemployment-rate sitesinden erişildi.

Trading Economics, (2020b). Bulgaria unemployment rate. 23.07.2020 tarihinde https://tradingeconomics.com/bulgaria/unemployment-rate sitesinden erişildi.

Trading Economics, (2020c). China urban survey unemployed rate.23.07.2020 tarihinde https:/tradingeconomics.com/china/unemployment-rate sitesinden erişildi.

Trading Economics, (2020d). Germany unemployment rate. 23.07.2020 tarihinde https://tradingeconomics.com/germany/unemployment-rate sitesinden erişildi.

Trading Economics, (2020e). Inflation rate. 25.07.2020 tarihinde https://tradingeconomics.com/ sitesinden erişildi.

Trading Economics, (2020f). Italy unemployment rate. 23.07 .2020 tarihinde https://tradingeconomics.com/italy/unemployment-rate sitesinden erişildi.

Trading Economics, (2020g). Turkey unemployment rate. 23.07.2020 tarihinde https://tradingeconomics.com/turkey/unemployment-rate sitesinden erişildi.

Trading Economics, (2020h). United States unemployment rate. 23.07.2020 tarihinde https://tradingeconomics.com/united-states/unemployment-rate sitesinden erişildi.

Ünalp Çepel, Zühal, (2020). Neoliberalizmin kovid-19 testi ve Avrupa Birliği: Dezavantajlı gruplar örneği. Ulisa: Uluslararası Çalışmalar Dergisi, 4(1), 3350.

Yıldırım, S. (2010). 2008 yılı küresel ekonomi krizinin Dünya ve Türkiye ekonomisine etkileri. Karamanoğlu Mehmetbey Üniversitesi Sosyal ve Ekonomik Araştırmalar Dergisi, 1, 47-55. 


\section{Kaynakça Bilgisi / Citation Information}

Örki, A., Tol, M. A. ve Arıkan, N. (2021). 2020 küresel ekonomik krizi ve kendi kendine yeterli olma konusunda farklı yaklaşımlar: 2020 Ocak - 2020 Mayıs. OPUS-Uluslararası Toplum Araştırmaları Dergisi, 17(Pandemi Özel Sayıs1), 3673-3698. DOI: 10.26466/opus. 776585 